Received 00th January 20xx, Accepted 00th January 20xx DOI: $10.1039 / x 0 x x 00000 x$

\title{
Atmospheric Water triggers Supramolecular Gel Formation of Novel Low Molecular Weight Maslinic and Oleanolic Triterpenic Derivatives
}

\begin{abstract}
Karina Vega-Granados, ${ }^{a}$ Gloria Belén Ramírez Rodríguez, ${ }^{\mathrm{b}}$ Rafael Contreras-Montoya, ${ }^{\text {a }}$ Francisco J. Ramírez, ${ }^{\mathrm{C}}$ Luis Palomo, ${ }^{\mathrm{c}}$ Andrés Parra, ${ }^{\mathrm{a}}$ Jose M. Delgado-López, ${ }^{\mathrm{b}}$ Modesto T. Lopez-Lopez, ${ }^{\mathrm{d}, \mathrm{e}}$ and Luis Álvarez de Cienfuegos*a,e

Pentacyclic triterpenes have a rigid lypophilic backbone decorated with polar functional groups such as hydroxyl, carbonyl and carboxyl, which make them attractive natural amphiphiles. The ability of this type of compounds to self-assemble into complex nanostructures has recently gained interest due in part to the abundant existing renewable feedstock. Herein, we present two new Maslinic and Oleanolic triterpenes pentacyclic derivatives that have the ability to self-assemble into long fibers giving rise to homogeneous gels. Quite remarkable these molecules are able to form gels by slowly capturing atmospheric water from their DMSO and DMF solutions. To the best of our knowledge, this mechanism of gel formation has not been previously reported for others LMWGs and highlights the versatility of these compounds to form gels as a response to different external stimuli. The micro- and macroscopic properties of the resulting gels have been studied in detail by TEM, SEM, NMR, VCD, FTIR, XRD and rheology. We have demonstrated that gels prepared by capturing atmospheric water in DMSO are more homogeneous and stiffer than those obtained by direct addition of water to the organic solution.
\end{abstract}

\section{Introduction}

Low molecular weight gelators (LMWGs) are a particular class of compounds that have the ability to efficiently self-assemble into supramolecular structures being able to retain solvent molecules giving rise to gels. ${ }^{1-3}$ Since the self-assembly nature of these molecules is promoted by non-covalent bonds, mainly Van der Waals forces, the resulting gels, in most of the cases, are reversible, being able to respond to external stimuli such as, temperature, $\mathrm{pH}$, sonication, chemical additives, etc.... ${ }^{4-6}$ At such, promising applications have been anticipated for this kind of materials as templates for the growth of inorganic particles, biomaterials, catalysts, sensors and optoelectronic devices. ${ }^{7-10}$ To date it is not possible to anticipate the structural requirements for a given molecule to behave as LMWG or to predict in which solvent or solvents will form a gel. Intensive efforts have been focused on discovering new LMWGs and trying to link their chemical composition with their capacity to self-assemble. ${ }^{11,12}$ Among the type of structures studied, LMWGs based on steroids have been particularly successful. ${ }^{13}$ Pioneering works of Weiss and co-workers in cholesterol based organic gelators showed that structures comprising an aromatic

\footnotetext{
a. Dpto de Química Orgánica, Facultad de Ciencias, Universidad de Granada (UGR), 18071-Granada, Spain.E-mail: lac@ugr.es

b. Dpto de Química Inorgánica, Facultad de Ciencias, (UGR).

c. Dpto de Química Física, Universidad de Málaga, (UMA), 29071-Málaga, Spain.

d. Dpto de Física Aplicada, Facultad de Ciencias, (UGR).

e. Instituto de Investigación Biosanitaria ibs.GRANADA, (UGR), Spain

+ Electronic Supplementary Information (ESI) available: Copies of ${ }^{1} \mathrm{H}-\mathrm{NMR}$ spectra of compounds and Supplementary figures. See DOI: 10.1039/x0xx00000x
}

moiety (A) connected to a steroidal group (S) via a linker (L) displayed an effective gelation ability. ${ }^{1}$ Derivatives based on $A(L S) 2-$ or LS2-type structures have also shown an effective gelation ability. ${ }^{14-16}$ Bile acids derivatives are also another group of steroid derivatives that have been in-depth studied showing the capacity to form organo- and hydrogels. ${ }^{13}$ In both cases, Van der Waals interactions between the rigid polycyclic steroid backbones favour the self-association of the molecules and promote the anisotropic growth in long fibers needed to form gels. In the last decade, efforts have been focused in studying the self-assembly properties of another structural-related family of natural compounds, the triterpenes. ${ }^{17}$ Triterpenes are vastly present in plants and, similar to steroids, contain a polycyclic rigid skeleton. The interest on these compounds lies in the broad diversity of therapeutic properties, such as, antitumor, anti-virus, anti-inflammatory and anti-microbial. ${ }^{18-20}$ Moreover, some of these derivatives can be easily isolated in large quantities from their natural feedstock making them a very attractive alternative, not only in the search of new therapeutics, but also in the field of material science since they can evolve into novel nanomaterials obtained from renewable sources. In this regard, the self-assembly ability of these triterpenes has been reported in isolated natural compounds ${ }^{21-}$ 24 and also in derivatives. ${ }^{25-27}$ They have been able to form chiral helical fibers, ${ }^{28}$ nanorods ${ }^{27}$ and vesicles $22,24,25$ in organic and mixtures of organic and aqueous solvents. ${ }^{17}$ Most of these compounds are able to form supramolecular aggregates by a heating and cooling cycle or by a change in the proportion of solvent mixtures. The versatility of these supramolecular 
aggregates has been exploited in the generation of advances materials, ${ }^{29,30}$ in catalysis, ${ }^{31}$ and drug carriers. ${ }^{32}$

Considering this, we focused our attention on pentacyclic triterpenic Maslinic (MA) and Oleanolic (OA) Acids, vastly present in the fruits of Olea europaea, and easily isolated and purified from the industrial olive-oil waste (Figure 1). ${ }^{19}$ These compounds have a carboxylic group that can be conveniently modified to obtain derivatives. At such, we reasoned that the introduction of an aromatic group through this carboxylic group could generate a structure resembling a similar ALS type of gelator. Trying to do this, when we activated the carboxylic group of $\mathrm{MA}$ and $\mathrm{OA}$ with $N, N, N^{\prime}, N^{\prime}$-Tetramethyl-O(benzotriazol-1-yl)uranium tetrafluoroborate (TBTU) we obtained the corresponding TBTU activated acids (MATBTU compound 1, and OATBTU compound 2) that, unexpectedly, not only formed stable compounds but were also able to form homogeneous gels in DMSO- $\mathrm{H}_{2} \mathrm{O}, \mathrm{DMF}-\mathrm{H}_{2} \mathrm{O}$ and compound $\mathbf{1}$ also in toluene (Figure 1).

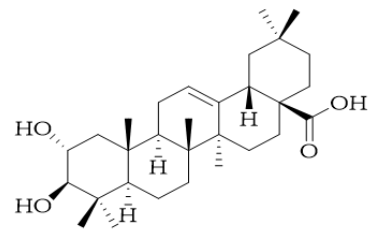

Maslinic acid

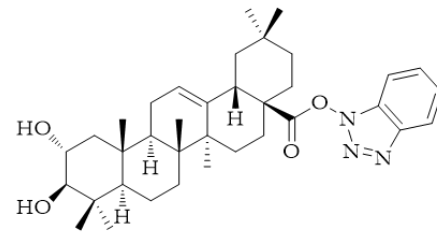

1 (MATBTU)

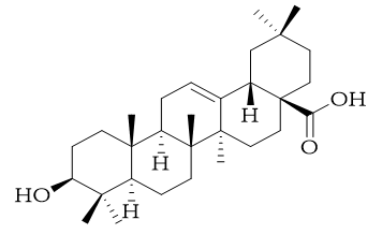

Oleanolic acid
Figure 1. Structures of Maslinic and Oleanolic acids and their gelator derivatives $\mathbf{1}$ and $\mathbf{2}$

More interestingly, these compounds were able to form homogeneous gels by two different strategies, those are: direct addition of water to their DMSO and DMF solutions or by slowly capturing atmospheric water from their respective solutions. The kinetics of gel formation of both processes, direct addition and slowly water capturing, differ significantly. When water is immediately added to the DMSO solution the gel forms in 5 minutes, whilst gel formation requires much more time when it captures atmospheric water. The gelification time of this second process depends on the gelator concentration. Gels formed in this way are more homogeneous being much stiffer than gels formed by direct addition of water. Additionally, this second process is able to form homogeneous gels with higher gelator concentration giving rise to more rigid self-supported gels. To the best of our knowledge, gel formation by capturing atmospheric water has not been previously described for other LMWGs and highlights the versatility of these compounds to form gels under different type of stimuli. In this case, several requirements have to be achieved by a small compound to be able to gelify. First, the gelator must be able to form a gel at room temperature; second, it must be able to form a gel in the mixture of the resulting combination of solvents, that is, DMSO$\mathrm{H}_{2} \mathrm{O}$ or DMF- $\mathrm{H}_{2} \mathrm{O}$; third, it must be able to form a gel in the adequate proportion of solvents, that, in this case, is also subjected to the hygroscopic character of the organic solvent. And fourth, to generate homogeneous gels, the kinetics of the self-association of the gelator molecules must be compatible with the rate of atmospheric water dissolution in the organic solvent.

Herein, we have studied in detail the gelification ability of compounds 1 (MATBTU) and $\mathbf{2}$ (OATBTU) in different solvents as well as the micro- and macroscopic properties of the resulting gels by TEM, SEM, ${ }^{1} \mathrm{H}-\mathrm{NMR}, \mathrm{FTIR}, \mathrm{VCD}, \mathrm{XRD}$, and rheology. Interestingly, compound $\mathbf{1}$ is able to form gels not only in DMSO- $\mathrm{H}_{2} \mathrm{O}$ and DMF- $\mathrm{H}_{2} \mathrm{O}$ but also in neat toluene. In this solvent, compound $\mathbf{1}$ forms different supramolecular aggregates than those obtained in DMSO- $\mathrm{H}_{2} \mathrm{O}$ and DMF- $\mathrm{H}_{2} \mathrm{O}$. A model of a supramolecular packing of compound $\mathbf{1}$ in toluene has been proposed using XRD data and theoretical computation.

\section{Experimental}

\section{Reagents and materials}

Oleanolic (3 $\beta$-hydroxyolean-12-en-28-oic acid, OA) and Maslinic ( $2 \alpha, 3 \beta$-dihydroxyolean-12-en-28-oic acid, MA) acids were isolated from solid wastes resulting from olive-oil production, which were extracted in a Soxhlet with hexane (Merck, ref. 1.04374) and EtOAc (Fisher Scientific, ref. E/0900/17) successively. ${ }^{19}$ Both acids were purified from these mixtures by flash chromatography over silica gel 60 (Merck, ref. 1.09385), eluting with $\mathrm{CH}_{2} \mathrm{Cl}_{2}$ (Fisher Scientific, ref. D/1852/17), with increasing amounts of acetone (Fisher Scientific, ref. A/0600/17). ${ }^{33}$ For the control of flash chromatography and reactions, silica gel 60 aluminum sheets (Merk. ref. 1.16835) were used, the compounds were made visible by spraying a mixture of $\mathrm{H}_{2} \mathrm{SO}_{4}$ and $\mathrm{AcOH}$, followed by heating at $120^{\circ} \mathrm{C}$, and finally observed with UV light at $254 \mathrm{~nm}$.

\section{Synthesis of the gelators}

$\mathrm{N}, \mathrm{N}$-Diisopropylethylamine (DIEA) $0.3 \mathrm{mmol}$ (Sigma-Aldrich, $\geq 99 \%$, ref. D125806), and O-(Benzotriazol-1-yl)- $N, N, N^{\prime}, N^{\prime}$ tetramethyluronium tetrafluoroborate (TBTU) $0.66 \mathrm{mmol}$ (Apollo Scientific, ref. PC0921), were added to each solution of triterpene $\mathrm{MA}$ and $\mathrm{OA}$, the solution was prepared with 0.44 $\mathrm{mmol}$ in THF $(20 \mathrm{~mL})$. The reactions were maintained at room temperature for 12 hours, and then extracted several times with water and $\mathrm{CH}_{2} \mathrm{Cl}_{2}$. The organic phase was dried with anhydrous $\mathrm{Na}_{2} \mathrm{SO}_{4}$ and the solvent was removed under reduced pressure. Finally, each residue was purified by column chromatography using hexane/EtOAc as eluents, obtaining the compounds 1 ( $92 \%$ yield) and $\mathbf{2}$ (90\% yield). ${ }^{34}$ For compound $\mathbf{1}$ ${ }^{1} \mathrm{H}-\mathrm{NMR}:\left(\mathrm{CDCl}_{3} 500 \mathrm{MHz}\right): 8.05$ (m, 1H, TBTU group), 7.52 
(m,1H, TBTU group), 7.38 (m, 2H, TBTU group), $5.38\left(\mathrm{dd}, 1 \mathrm{H}, J_{1}\right.$ $\left.=J_{2}=3.6 \mathrm{~Hz}, \mathrm{H}-12\right), 3.69$ (ddd, $1 \mathrm{H}, J_{1}=4.4, J_{2}=10.0, J_{3}=14.4 \mathrm{~Hz}$ $\mathrm{H}-2$ ), 3.01 (d, $1 \mathrm{H}, J=10.0 \mathrm{~Hz}, \mathrm{H}-3), 2.98\left(\mathrm{dd}, 1 \mathrm{H}, J_{1}=4.0, J_{2}=13.5\right.$ $\mathrm{Hz}, \mathrm{H}-18$ ), 1.22, 1.05, 1.00, 0.98, 0.97, 0.85, 0.84 (s, 3H each, methyl groups); ${ }^{13} \mathrm{C}-\mathrm{NMR}\left(\mathrm{CDCl}_{3}, 100 \mathrm{MHz}\right): 16.8\left(\mathrm{CH}_{3}\right), 16.9$ $\left(\mathrm{CH}_{3}\right), 17.5\left(\mathrm{CH}_{3}\right), 18.5\left(\mathrm{CH}_{2}\right), 23.3\left(\mathrm{CH}_{2}\right), 23.7(\mathrm{CH}), 23.7\left(\mathrm{CH}_{3}\right)$, $25.9\left(\mathrm{CH}_{3}\right), 28.2\left(\mathrm{CH}_{2}\right), 28.8\left(\mathrm{CH}_{3}\right), 30.8(\mathrm{C}), 32.6\left(\mathrm{CH}_{2}\right), 32.9\left(\mathrm{CH}_{2}\right)$, $33.1\left(\mathrm{CH}_{3}\right), 33.8\left(\mathrm{CH}_{2}\right), 38.4(\mathrm{C}), 39.3(\mathrm{C}), 39.7(\mathrm{C}), 41.7(\mathrm{CH}), 42.1$ (C), $45.6\left(\mathrm{CH}_{2}\right), 46.6\left(\mathrm{CH}_{2}\right), 47.7(\mathrm{CH}), 47.8(\mathrm{C}), 55.5(\mathrm{CH}), 69.0$ (CH), $84.1(\mathrm{CH}), 108.3$ (CH TBTU), 120.7 (CH TBTU), $123.9(\mathrm{CH})$, 124.8 (CH TBTU), 128.6 (CH TBTU), 128.9 (C TBTU), 142.3 (C), 143.7 (C TBTU), 173.7 (COOH); ESI-HRMS m/z calcd for $\mathrm{C}_{36} \mathrm{H}_{52} \mathrm{~N}_{3} \mathrm{O}_{4}[\mathrm{M}+1]^{+} 590.3958$, found 590.3954 .

For compound $2^{1} \mathrm{H}-\mathrm{NMR}$ : ( $\left.\mathrm{CDCl}_{3}, 500 \mathrm{MHz}\right): 8.03(\mathrm{~m}, 1 \mathrm{H}, \mathrm{TBTU}$ group), 7.50 ( $\mathrm{m}, 1 \mathrm{H}$, TBTU group), 7.37 (m, 2H, TBTU group), $5.36\left(\mathrm{dd}, 1 \mathrm{H}, J_{1}=J_{2}=3.5 \mathrm{~Hz}, \mathrm{H}-12\right), 3.20\left(\mathrm{dd}, 1 \mathrm{H}, J_{1}=4.0, J_{2}=\right.$ $11.0 \mathrm{~Hz}, \mathrm{H}-3$ ), 2.97 (dd, $1 \mathrm{H}, J_{1}=4.5, J_{2}=14.0 \mathrm{~Hz}, \mathrm{H}-18$ ), 1.21 , $0.99,0.98,0.96,0.89,0.84,0.78$ (s, 3H each, methyl groups); ${ }^{13} \mathrm{C}$-NMR: $\left(\mathrm{CDCl}_{3}, 125 \mathrm{MHz}\right): 15.5\left(\mathrm{CH}_{3}\right), 15.7\left(\mathrm{CH}_{3}\right), 17.4\left(\mathrm{CH}_{3}\right)$, $18.4\left(\mathrm{CH}_{2}\right), 23.2\left(\mathrm{CH}_{2}\right), 23.6(\mathrm{CH}), 23.6\left(\mathrm{CH}_{3}\right), 25.8\left(\mathrm{CH}_{3}\right), 27.3$ $\left(\mathrm{CH}_{2}\right), 28.2\left(\mathrm{CH}_{2}\right), 28.2\left(\mathrm{CH}_{3}\right), 30.7(\mathrm{C}), 32.5\left(\mathrm{CH}_{2}\right), 32.9\left(\mathrm{CH}_{2}\right), 33.0$ (CH3), $33.8\left(\mathrm{CH}_{2}\right), 37.1(\mathrm{C}), 38.7\left(\mathrm{CH}_{2}\right), 38.9(\mathrm{C}), 41.7(\mathrm{CH}), 42.0$ (C), $45.6\left(\mathrm{CH}_{2}\right), 47.7(\mathrm{CH}), 47.7(\mathrm{C}), 55.3(\mathrm{CH}), 79.0(\mathrm{CH}), 108.3$ (CH TBTU), 120.6 (CH TBTU), 124.0 (CH), 124.7 (CH TBTU), 128.6 (CH TBTU), 128.9 (CH TBTU), 142.2 (C), 143.6 (CH TBTU), 173.7 (COOH); ESI-HRMS m/z calcd for $\mathrm{C}_{36} \mathrm{H}_{52} \mathrm{~N}_{3} \mathrm{O}_{3}[\mathrm{M}+1]^{+} 574.4009$, found 574.4020 .

\section{Gelification protocol}

To prepare gels in mixtures DMSO- $\mathrm{H}_{2} \mathrm{O}$ or DMF- $\mathrm{H}_{2} \mathrm{O}$, the desired amount of powder of $\mathbf{1}$ or $\mathbf{2}$ was weighted in a sample tube and DMSO or DMF was then added to reach the final concentration. The mixture was gently warmed until a clear solution was obtained and it was left to reach room temperature. To prepare gels by capturing water, gelator solution in open vials was left exposed to the lab environment different times depending on the gel concentration (Table S1, ESI). Gels prepared by direct addition of water, water was added to the solution and the gelation was completed in 5 minutes in the case of DMSO- $\mathrm{H}_{2} \mathrm{O}$ and 90 minutes in the case of DMF- $\mathrm{H}_{2} \mathrm{O}$.

Gels of 1 containing toluene were prepared by adding toluene to reach a gelator concentration of $1.6 \%(\mathrm{w} / \mathrm{v})$. The mixture was gently warmed to dissolve the gelator and the gels were obtained when the solution reached room temperature, approx. 5 minutes.

\section{Scanning Electron Microscopy (SEM)}

Samples containing DMSO- $\mathrm{H}_{2} \mathrm{O}$ or DMF- $\mathrm{H}_{2} \mathrm{O}$ were freeze dried. Samples containing toluene were dried by air-drying exposing a gel portion to the lab environment overnight and by 'critical point drying' (CPD). For CPD, a gel portion was sequentially soaked in different mixtures of toluene and ethanol, increasing the ethanol proportion until all the toluene was replaced by ethanol. Then, the sample was placed in the chamber of the CPD equipment Polaron CPD 7501. The chamber was sealed and cooled and the solvent was removed with supercritical $\mathrm{CO}_{2}$. The sample was covered with carbon with the high vacuum thermal evaporator EMITECH K975X. All samples dried, as described above, were studied by using a FEI Quanta 400 ESEM electron microscope.

\section{Transmission Electron Microscopy (TEM)}

TEM images were recorded by using a LIBRA 120 PLUS (Carl Zeiss) electron microscope. For all samples, a little portion of gel was dispersed in water using an ultrasonic bath and a drop of the aqueous suspension was placed on a carbon-coated copper grid (300-mesh). The samples were dried at room temperature overnight.

\section{${ }^{1} \mathrm{H}-$ Nuclear Magnetic Resonance $\left({ }^{1} \mathrm{H}-\mathrm{NMR}\right)$}

NMR gel samples at $1 \%(\mathrm{w} / \mathrm{v})$ were prepared at room temperature by adding $\mathrm{D}_{2} \mathrm{O}(15 \%, 0.15 \mathrm{~mL})$ to a solution of 1 or 2 in DMSO- $d^{6}(0.85 \mathrm{~mL})$ contained in a $5 \mathrm{~mm}$ NMR tube.

NMR spectra corresponding to the relaxation experiments were recorded in a $600 \mathrm{MHz}$ (Agilent VNMRS software VnmrJ-4.2A) instrument at $25^{\circ} \mathrm{C}$ (gel state) and at $100^{\circ} \mathrm{C}$ (solution state). $T_{2}$ measurements were performed using the Carr-PurcellMeiboom-Gill (CPMG2) sequence with dephasing times of 0.4 ms. A minimum of nine points was obtained for each of the relaxation experiments, and a good fit of the data to an exponential decay was obtained in all reported data.

\section{Fourier transform Infrared (FTIR) spectroscopy}

FTIR Spectra were recorded in a Tensor 27 (Bruker) spectrometer equipped with an Attenuated Total Reflection (ATR) accessory (diamond, 1 reflection, $45^{\circ}$ ). The hydrogels were pressed against the diamond crystal. The spectra are the results of averaging 25 scans collected in the range between 4000 and $500 \mathrm{~cm}^{-1}$ with a resolution of $2 \mathrm{~cm}^{-1}$. A spectrum of air was used as background.

\section{Vibrational Circular Dichroism (VCD)}

VCD spectra were measured by means of a Bruker PMA50 optical bench coupled to the Vertex 70 spectrometer. In the PMA50 instrument, the infrared radiation is focused by a $\mathrm{BaF}_{2}$ lens, passing an optical filter (3800-600 $\mathrm{cm}^{-1}$ range) and a $\mathrm{ZnSe}$ photoelastic modulator (PM, $50 \mathrm{kHz}$ frequency). The light beam is finally collected by a D313/QMTC detector with non-dichroic $\mathrm{BaF}_{2}$ windows. Previous calibration of the $P M$ at a fixed wavenumber is required before recording a VCD spectrum. A spectral region of $600 \mathrm{~cm}^{-1}$ centred on each calibration wavenumber is then available. Typically, calibrations at 1300 $\mathrm{cm}^{-1}$ allowed us to obtain VCD signal over the infrared region in which we are interested. Every VCD spectrum was the result of averaging a minimum of 28000 scans ( $12 \mathrm{~h}$ acquisition times) at a spectral resolution better than $4 \mathrm{~cm}^{-1}$.

VCD spectra were recorded from gels formed in DMSO- $\mathrm{H}_{2} \mathrm{O}$ at a concentration $310^{-3} \mathrm{M}$. The gels were placed in a variable path 
liquid cell of $0.015 \mathrm{~mm}$ length and $\mathrm{KBr}$ windows. Measurements and spectral treatments were carried out using the OPUS 6.5 (C) spectroscopic software.

\section{DFT Calculations}

The Gaussian'16 suite of programs ${ }^{35}$ was used to carry out Density Functional Theory (DFT) quantum chemical calculations. The hybrid exchange-correlation functional b3lyp was used in all calculations. It combines the Becke's three parameter (b3) gradient-corrected exchange functional and the Lee-Yang-Parr (lyp) non-local correlations. ${ }^{36-38}$ Ground state structures were calculated using the cc-pvdz double-zeta Dunning's correlation consistent basis sets, ${ }^{39}$ which includes polarization functions by definition. The theoretical infrared and VCD spectra were obtained from the DFT intensities in combination with the calculated vibrational wavenumbers uniformly scaled by 0.98 . Every band was represented by a Gaussian function of $10 \mathrm{~cm}^{-1}$ half-height width.

\section{X-Ray Diffraction (XRD)}

X-ray powder diffraction (XRPD) patterns of the samples were collected on a Bruker D8 Discover diffractometer $\mu$ MR (Bruker, Karlsruhe, Germany) equipped with a DECTRIS PILATUS3 $R$ 100K-A hybrid photon counting (HPC) 2D detector. Measurements were carried out using $\mathrm{Cu} K \alpha$ radiation $(\lambda=$ $1.5406 \AA$ A) generated at $50 \mathrm{kV}$ and $1 \mathrm{~mA}$. Patterns were recorded in the $2 \theta$ range from 3 to $45^{\circ}$ with a step size $(2 \theta)$ of 0.02 . As prepared gels were deposited on a zero-diffraction silicon plate.

\section{Rheological characterization}

For the characterization of the dynamic rheological properties of the gels we used a controlled-stress Haake Mars III rheometer, provided with two different sets of geometries (parallel plates of $35 \mathrm{~mm}$ of diameter and coaxial cylinders of 16 $\mathrm{mm}$ and $17 \mathrm{~mm}$ of internal and external diameter, respectively). We subjected all samples to oscillatory shear strains and measured the resulting oscillatory shear stresses at a temperature of $25{ }^{\circ} \mathrm{C}$. From these measurements we obtained the viscoelastic moduli of the samples: storage modulus $\left(G^{\prime}\right)$ and loss modulus $\left(G^{\prime \prime}\right)$. For obtaining a complete characterization of the rheological properties in the regime of oscillatory shear strain, we performed two separate experiments. First, amplitude sweeps, of fixed frequency of oscillations and stepwise increasing shear strain amplitude, which allowed the determination of the extension of the linear viscoelastic regime (LVR). Then, frequency sweeps of fixed amplitude of shear strain within the LVR and stepwise increasing frequency. In addition, we determined by rheological methods the temperature ( $\left.T_{\text {gel }}\right)$ at which the gel-sol transition of the gels took place. For this aim we placed the gels in the measuring system of the rheometer at room temperature and increased the temperature $2.5^{\circ} \mathrm{C} / \mathrm{min} \pm 0.97$, up to $85^{\circ} \mathrm{C}$. The samples were subjected to oscillatory shear strains of fixed frequency $(1 \mathrm{~Hz})$ and fixed amplitude within the LVR and monitored the temperature-evolution of the viscoelastic moduli of the gels.

For each sample and experimental condition, we conducted at least 3 separate measurements. Results shown in this manuscript represent the average of each set of separate measurements.

\section{Results and discussion}

\section{Gelation behaviour of the compounds}

The gelation behavior of compounds 1 (MATBTU) and 2 (OATBTU) were tested in 37 solvents at a concentration of $1 \%$ $(w / v)$, and the results are listed in Table 1 . Gelification tests were performed following different strategies. Firstly, compounds were tried to be dissolved at room temperature through the application of sonication. Secondly, compounds were tried to be dissolved by temperature switch, in which the temperature was raised until complete dissolution of the gelator and, thirdly, compounds were tried to be dissolved by solvent switch, mixing the gelator solution with a solvent in which the gelator is not soluble. Of all the solvents tested, compounds $\mathbf{1}$ and $\mathbf{2}$ were able to form homogeneous gels at room temperature by solvent switch in DMSO- $\mathrm{H}_{2} \mathrm{O}, \mathrm{DMF}-\mathrm{H}_{2} \mathrm{O}$ and $\mathbf{1}$ in toluene by temperature switch.

Table 1. Gelation performances of $\mathbf{1}$ (MATBTU) and $\mathbf{2}$ (OATBTU) in various organic solvents. ${ }^{a}$

\begin{tabular}{|c|c|c|c|c|c|}
\hline Solvent & 1 & 2 & Solvent & 1 & 2 \\
\hline Acetone & PG & $S$ & $\begin{array}{c}\text { DMSO (85\%) } \mathrm{H}_{2} \mathrm{O} \\
(15 \%)\end{array}$ & G & G \\
\hline Ethyl acetate & $S$ & $S$ & Ethanol & PG & PG \\
\hline Acetonitrile & $\mathrm{S}$ & $S$ & Diethyl ether & I & $\mathrm{S}$ \\
\hline Acetophenone & S & $S$ & n-Hexane & I & PG \\
\hline Benzene & PG & S & n-Heptane & 1 & PG \\
\hline n-Butanol & S & S & Isooctane & I & $\mathrm{S}$ \\
\hline Butanone & $S$ & $S$ & Isopropanol & PG & $\mathrm{S}$ \\
\hline Butyl glycolate & $S$ & S & Methanol & PG & I \\
\hline Chlorobenzene & $P$ & $S$ & Methyl acetate & S & $\mathrm{S}$ \\
\hline Chloroform & $\mathrm{S}$ & S & 2-Methylfuran & PG & $\mathrm{S}$ \\
\hline Cyclohexane & $P$ & PG & $\begin{array}{l}\text { 1-Methyl-2- } \\
\text { pyrrolidone }\end{array}$ & $\mathrm{S}$ & $\mathrm{S}$ \\
\hline Cyclopentane & $P$ & PG & Nitromethane & S & $\mathrm{S}$ \\
\hline Cyclopentanone & $S$ & $S$ & Octane & 1 & PG \\
\hline 1,2-Dichloroethane & $S$ & S & Pentane & 1 & $P$ \\
\hline Diisopropyl ether & 1 & $S$ & 1-Propanol & $S$ & $\mathrm{~S}$ \\
\hline Dichloromethane & $S$ & S & Tetrahydrofuran & $S$ & $\mathrm{~S}$ \\
\hline DMA & $\mathrm{S}$ & $S$ & Tetrahydropyran & $S$ & $\mathrm{~S}$ \\
\hline Methylformamide & $S$ & $S$ & Toluene & TG & $\mathrm{S}$ \\
\hline $\begin{array}{c}\text { DMF }(75 \%) \mathrm{H}_{2} \mathrm{O} \\
(25 \%) \text { 1. DMF (86\%) }\end{array}$ & G & G & & & \\
\hline
\end{tabular}
$\mathrm{H}_{2} \mathrm{O}(14 \%) 2$

a Concentration of gelator: $1 \% \mathrm{w} / \mathrm{v}$; G: gels forming at room temperature; $\mathrm{S}$ : solution; PG: partial gel; I: insoluble; TG: turbid gel; P: precipitate. 
In DMSO- $\mathrm{H}_{2} \mathrm{O}$ compounds $\mathbf{1}$ and $\mathbf{2}$ were able to form gels in concentrations ranging from $1 \%$ to $10 \%(\mathrm{w} / \mathrm{v})$ giving rise to homogeneous gels of increasing opacity (Figure 2). At all gelator concentrations tested the amount of absorbed water was always the same. By weighting the vials containing the DMSO gelator solution and the resulting gels we quantified that the amount of absorbed water was $15 \%(\mathrm{v} / \mathrm{v})$. This amount of water agrees with the water that DMSO solvent is able to absorb at room temperature. ${ }^{40}$

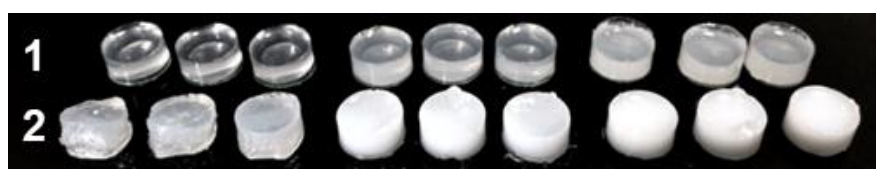

Figure 2. Gels of $\mathbf{1}$ and $\mathbf{2}$ in DMSO- $\mathrm{H}_{2} \mathrm{O}$ at increasing concentrations of gelators. From left to right: gels 1 to 3 are at $1 \%(\mathrm{w} / \mathrm{v})(10 \mathrm{mg} / \mathrm{mL}), 4$ to 6 are at $4 \%(\mathrm{w} / \mathrm{v})(40 \mathrm{mg} / \mathrm{mL})$ and 7 to 9 are at $8 \%(\mathrm{w} / \mathrm{v})(80 \mathrm{mg} / \mathrm{mL})$.

Similarly, both compounds were also able to form homogeneous gels in $\mathrm{DMF}-\mathrm{H}_{2} \mathrm{O}$ although the range of concentrations were restrained from $4 \%$ to $10 \%(w / v)$. At a conc. of $10 \%(\mathrm{w} / \mathrm{v})$ the gel was opaque and gelator precipitation appeared. In this case, the amount of absorbed water was not the same for both gelators, see table S2, ESI. Compound 1 absorbed much more water than compound $\mathbf{2}$, as indicated in table 1 and table $\mathrm{S} 2$.

Compound 1 was also able to gelify toluene although, in this case, gelification only occurred at a unique concentration of $1.6 \%(\mathrm{w} / \mathrm{v})$ giving a whitish opaque gel. It is interesting to note that although these compounds are rather hydrophobic (1 clogP $=5.62$ and $2 \operatorname{cog} \mathrm{P}=6.86$ ) they are able to gelify very polar organic solvent mixtures, such as DMSO- $\mathrm{H}_{2} \mathrm{O}$ and $\mathrm{DMF}-\mathrm{H}_{2} \mathrm{O}$. Surprisingly, toluene, although classified as non-polar solvent, has a large permanent quadrupole moment and is able to form not only $\pi-\pi$ aromatic interactions but also polar- $\pi$ interactions with hydrogen bond donors. Although compound 1 differs from compound $\mathbf{2}$ only in the presence of an additional hydroxyl group (Figure 1), this small change is sufficient to influence the ability of these compounds to form supramolecular aggregates in a variety of organic solvents. While compound $\mathbf{1}$ was able to partially gelify highly polar and aromatic solvents, compound $\mathbf{2}$, on the contrary, was able to partially gelify non-polar solvents such as lineal hydrocarbons (table 1 ).

\section{Scanning Electron Microscopy (SEM) Imaging}

In order to study the impact of the solvent in the structure of the resulting network, SEM images of xerogels were taken. Xerogels were prepared by lyophilizing or air-drying gels of 1 and 2 at $1.6 \%(\mathrm{w} / \mathrm{v})$ in $\mathrm{DMSO}-\mathrm{H}_{2} \mathrm{O}(85 \% / 15 \%)$ and $\mathrm{DMF}-\mathrm{H}_{2} \mathrm{O}$ (75\%/25\% for 1 and $86 \% / 14 \%$ for 2). Gels were prepared by capturing atmospheric water. Additionally, xerogels from 1 prepared in toluene at the same concentration were obtained by CPD and air-drying methods.

SEM images of xerogels of the two compounds obtained from gels of DMSO- $\mathrm{H}_{2} \mathrm{O}$ (Figure $3 \mathrm{~A}, \mathrm{~B}$ ) and $\mathrm{DMF}-\mathrm{H}_{2} \mathrm{O}$ (Figure $3 \mathrm{C}, \mathrm{D}$ ) presented a similar morphology. Both samples showed a congested mesh of interwoven helical fibers with diameters ranging, preferentially, from 50 to $100 \mathrm{~nm}$, although fibers with higher diameters were also observed. These results indicated that gelators $\mathbf{1}$ and $\mathbf{2}$ gave rise to similar aggregates in these two solvents. In this case, the slightly different gelator structures practically have no influence in the final supramolecular structures formed. This might be explained by the similar character between DMF and DMSO, since both are polar aprotic solvents of similar dielectric constant. The high polarity of these solvents can favour the hydrophobic aggregation of these gelators through the triterpene backbone.

On the other hand, very different aggregates were obtained from the xerogels of $\mathbf{1}$ in toluene. SEM images of the CPD xerogel (Figure 3E) showed well-defined thick rods of larger diameters ranging from 100 to $400 \mathrm{~nm}$. In order to check if the different sample preparation protocol had an influence in the final morphology, samples prepared by air-drying, similarly as prepared by DMF- $\mathrm{H}_{2} \mathrm{O}$ and DMSO- $\mathrm{H}_{2} \mathrm{O}$, were also studied (Figure 3F). In this case, morphologies were identical to the sample prepared by CPD being very different to the morphologies obtained in the other solvents. It is not unusual for this type of gelators to present different morphologies in different solvents. Similar results have been obtained with cholesterol and triterpenes derivatives ${ }^{14,27}$ and highlights the dynamic no covalent nature of the self-aggregation process. In this case, the different polarity of toluene from mixtures of DMSO- $\mathrm{H}_{2} \mathrm{O}$ and DMF- $\mathrm{H}_{2} \mathrm{O}$ justifies the different morphology of the resulting supramolecular aggregates.
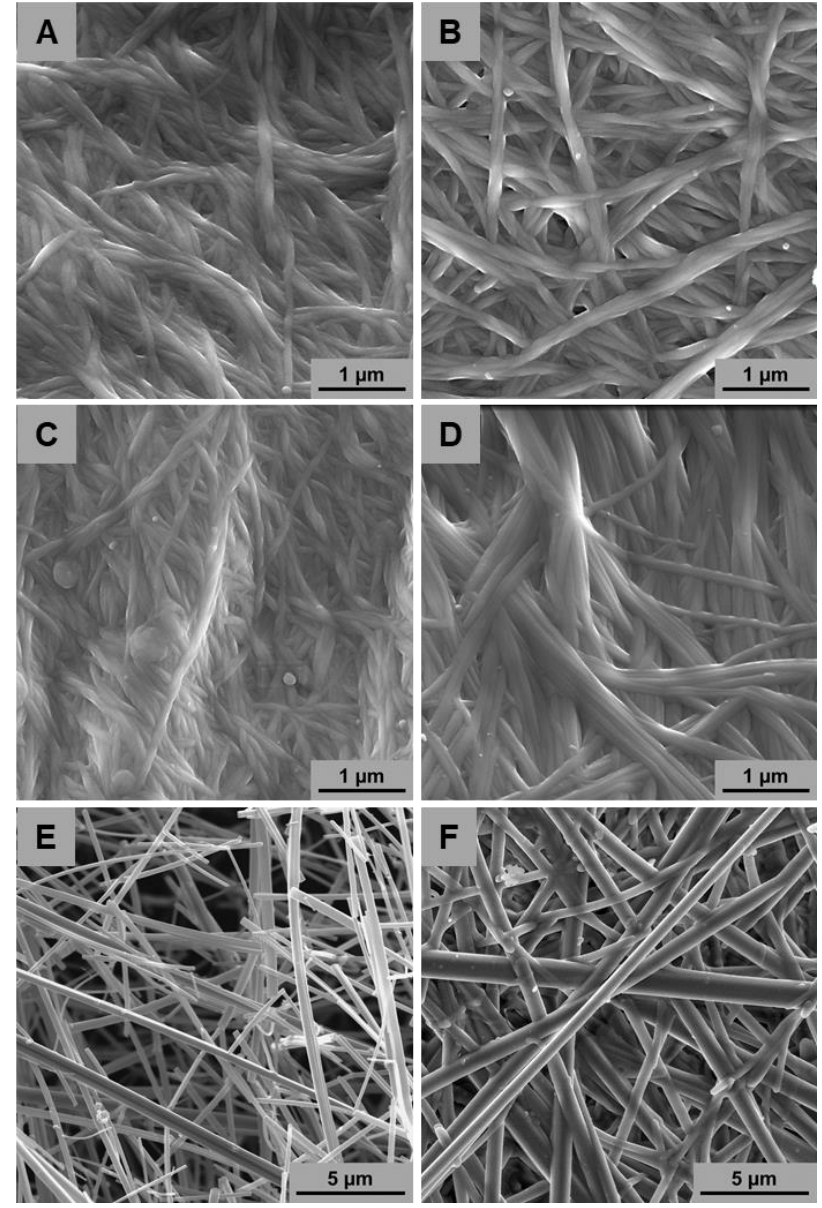
Figure 3. SEM images of xerogels $\mathbf{1}$ and $\mathbf{2}$ in DMSO- $\mathrm{H}_{2} \mathrm{O}$ (A and $\mathrm{B}$, respectively) and DMF$\mathrm{H}_{2} \mathrm{O}$ ( $\mathrm{C}$ and $\mathrm{D}$, respectively). Xerogel of $\mathbf{1}$ in toluene after supercritical drying $(\mathrm{E})$ and airdrying (F).

\section{Transmission Electron Microscopy (TEM) Imaging}

A similar trend was also observed in TEM images (Figure S1, ESI). In this case, only nanorods were observed for both compounds. The lengths and diameters of these nanorods were significantly affected by the solvent. At such, nanorods of smaller aspect ratio were formed in DMSO- $\mathrm{H}_{2} \mathrm{O}$ having diameters from 10 to $60 \mathrm{~nm}$ (Figure S1A, B). Nanorods formed in DMF- $\mathrm{H}_{2} \mathrm{O}$ showed larger dimensions with diameter ranges from 20 to $80 \mathrm{~nm}$ (Figure S1C, D). Not surprisingly, and resembling the structures observed by SEM, the most different nanorods were observed for $\mathbf{1}$ in toluene (Figure S1E). In this case, nanorods were the largest aspect ratio, reaching diameters larger than $500 \mathrm{~nm}$. Similar results have been observed in a pyridinium-oleanolate derivative in which the solvophobic effect between the solvents and the gelator is the main responsible of the aggregation and growth of the gelator molecules. ${ }^{27}$ In this case, toluene, being a non-polar solvent, promotes a stronger aggregation of $\mathbf{1}$ giving rise to nanorods of larger aspect ratio.

\section{VT-1 ${ }^{1} \mathbf{H}-$ Nuclear Magnetic Resonance (NMR) studies}

The temperature-dependent ${ }^{1} \mathrm{H}-\mathrm{NMR}$ spectra of $\mathbf{1}$ and $\mathbf{2}$ in DMSO- $d^{6}$ containing $15 \%$ of $\mathrm{D}_{2} \mathrm{O}$ are shown in Figure 4 . At room temperature $\left(25^{\circ} \mathrm{C}\right)$ the gel showed broad peaks of the molecule with unresolved J-couplings. The intensity of the signals suggested that only a fraction of the gelator molecules was observed by NMR since the gel network was NMR silent as a result of the large correlation time of the assemblies. As the temperature increased from $25^{\circ} \mathrm{C}$ to $100^{\circ} \mathrm{C}$ the spectra became much better resolved, all resonances sharpen and the spectra looked like as the monomer suggesting that $T_{\text {gel }}$ was surpassed. It can be noticed that there was practically no variation in the chemical shifts of all signals in the gel and sol states, although there was a modification of the tumbling rates ( $T_{2}$ values) upon gel formation (Table 2). This variation in the values of $T_{2}$ cannot be ascribed to possible changes in the viscosity of the media since it is known that supramolecular gelators do not affect the tumbling rates ${ }^{41}$ and the viscosity of the solvent. ${ }^{42}$ This phenomena has already been observed by other authors in closed related gelator structures such as cholesterol stilbene derivatives ${ }^{43}$ and suggests that there are mobile gel regions that can be observed by NMR. An alternative explanation of this effect has been proposed by Escuder and Miravet. ${ }^{41}$ These authors suggest that in these systems there is an exchange of the gelator molecules from the gel to the solution fast in the NMR relaxation times (seconds) and slow on the NMR time scale (milliseconds). In this way chemical shifts of the molecules would remain unchanged going from sol to gel since only free molecules would be observable while aggregates would not.

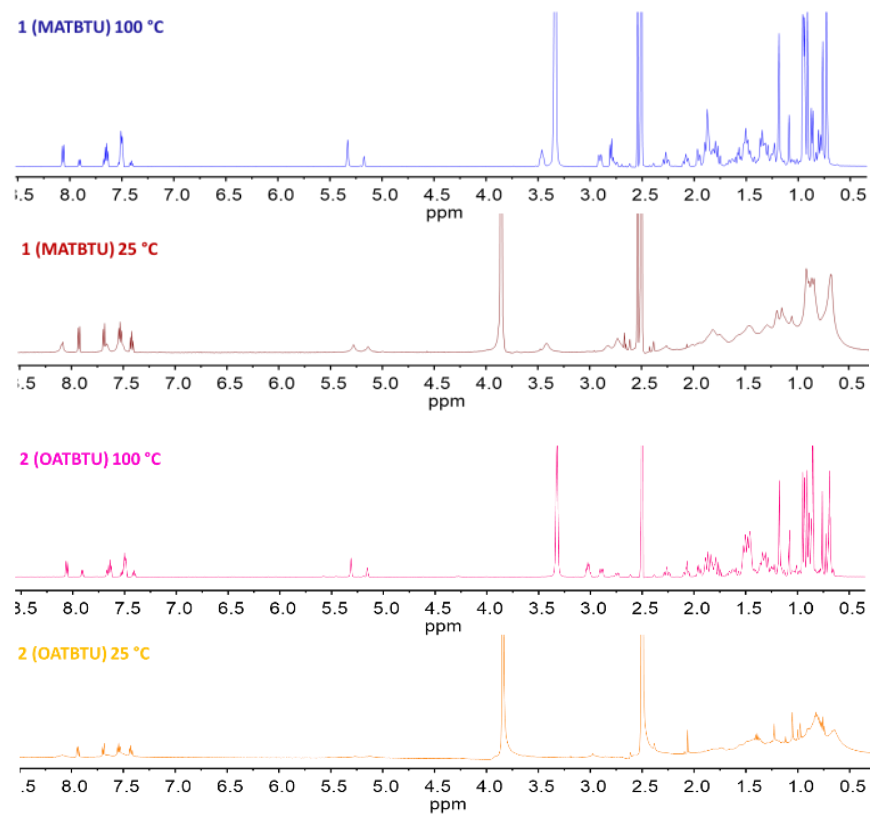

Figure 4. Temperature dependence of the ${ }^{1} \mathrm{H}-\mathrm{NMR}$ spectra of $\mathbf{1}$ and $\mathbf{2}$ in DMSO- $d^{6} / \mathrm{D}_{2} \mathrm{O}$.

Table 2. Selected Transversal $\left(T_{2}\right)^{1} \mathrm{H}$-NMR relaxation times measured for gelators 1 and 2 in DMSO- $d^{6} / \mathrm{D}_{2} \mathrm{O}$.

\begin{tabular}{cccc}
\hline \hline Gelator & $\begin{array}{c}\text { Temperature } \\
\left({ }^{\circ} \mathbf{C}\right)\end{array}$ & $\begin{array}{c}\text { Integration Peaks } \\
(\mathbf{p p m})\end{array}$ & $\mathbf{T}_{\mathbf{2}}(\mathbf{s})$ \\
\hline \hline $\mathbf{1}$ & $100(\mathrm{sol})$ & $7.43-7.38$ & 1.0045 \\
$\mathbf{1}$ & $100(\mathrm{sol})$ & $5.34-5.31$ & 0.3989 \\
$\mathbf{1}$ & $25(\mathrm{gel})$ & $7.44-7.39$ & 0.2376 \\
$\mathbf{1}$ & $25(\mathrm{gel})$ & $5.31-5.23$ & 0.1231 \\
$\mathbf{2}$ & $100(\mathrm{sol})$ & $7.43-7.39$ & 1.9865 \\
$\mathbf{2}$ & $100(\mathrm{sol})$ & $1.19-1.16$ & 0.4276 \\
$\mathbf{2}$ & $25(\mathrm{gel})$ & $7.45-7.40$ & 0.6059 \\
$\mathbf{2}$ & $25(\mathrm{gel})$ & $1.24-1.21$ & 0.2638 \\
\hline \hline
\end{tabular}

\section{Fourier transform Infrared (FTIR) spectroscopy}

FTIR spectra of gels of $\mathbf{1}$ in DMSO- $\mathrm{H}_{2} \mathrm{O}$ at increasing concentration of MATBTU, along with the spectra of pure MATBTU and DMSO, are shown in Figure 5a. The spectra of the gels are mainly dominated by the features of the organic solvent. The presence of water molecules in the gels is further confirmed by the stretching $\left(3300-3600 \mathrm{~cm}^{-1}\right.$ ) and bending (ca. $1650 \mathrm{~cm}^{-1}$ ) modes of water molecules. In addition, the peak at $1041 \mathrm{~cm}^{-1}$, assigned to the $\mathrm{S}=\mathrm{O}$ stretching mode of selfassociated DMSO molecules, ${ }^{44}$ is red-shifted up to ca. $1020 \mathrm{~cm}^{-}$ 1 in the gels (Figure $5 \mathrm{c}$ ). DMSO molecules self-associate through dipole-dipole interactions resulting in chain-like and cyclic structures. ${ }^{44}$ Water induces the formation of hydrogen-bonded DMSO- $\mathrm{H}_{2} \mathrm{O}$ dimers, which turns out in a red shift of the SO stretching. ${ }^{44}$ Indeed, in aqueous DMSO solutions, the frequency of the SO stretching coincides with that of the methyl rocking modes (ca. $1020 \mathrm{~cm}^{-1}$ ). For this reason, the overall intensity of the region around $1020 \mathrm{~cm}^{-1}$ is increased in the presence of 
water, ${ }^{44}$ as we observed in our FTIR spectra (Figure $5 \mathrm{c}$ ). In fact, the higher shift was found in the $1 \%(\mathrm{w} / \mathrm{v})$ gel, which contains the higher water/gelator ratio (Figure $5 \mathrm{a}, \mathrm{c}$ ). Therefore, the formation of the DMSO- $\mathrm{H}_{2} \mathrm{O}$ dimers, also occurring in the compound $\mathbf{2}$ in DMSO (Figure S2, ESI) could be the responsible of triggering the gelification by changing the solvophobic effect between the media and the gelator, not occurring when the gelator is dissolved in pure DMSO. Similar results were also found in mixtures of DMF- $\mathrm{H}_{2} \mathrm{O}$ (Figure S3, ESI).

Vibrational bands assignable to the gelator are visible at higher concentrations 8 and 15\% (w/v) (Figure 5a). Both 1 and 2 as DMSO- $\mathrm{H}_{2} \mathrm{O}$ gels showed an intense band at $1808 \mathrm{~cm}^{-1}$, which can be assigned to the stretching vibration of the carbonyl group, $v(C=O)$, according to DFT calculations. In the spectrum of 2 as a pure solid (Figure S4a, ESI) this band had a maximum at $1812 \mathrm{~cm}^{-1}$ and exhibited a clear shoulder at lower wavenumber, also visible in the gel. This could suggest the existence of different environments around the carbonyl group.

The water bending modes between 1750 and $1600 \mathrm{~cm}^{-1}$ prevented observing two weak absorptions (which were well predicted by DFT calculations), as the stretching vibrations of $\mathrm{C}=\mathrm{C}$ and benzotriazole moieties (Figure $\mathrm{S} 4 \mathrm{~b}, \mathrm{ESI}$ ). No differences were predicted for them when comparing $\mathbf{1}$ and $\mathbf{2}$. Most of the bands measured between 1500 and $1100 \mathrm{~cm}^{-1}$ were assigned to the bending vibrations of aliphatic $\mathrm{C}-\mathrm{H}$ bonds, largely methyl and methylene groups. On the basis of DFT calculations, the band at $1382 \mathrm{~cm}^{-1}$ in 1 can be also assigned to a benzotriazole stretching mode. The same band was measured at $1384 \mathrm{~cm}^{-1}$ for gels of 2.


Figure 5. FTIR spectra of MATBTU (1) hydrogels in DMSO- $\mathrm{H}_{2} \mathrm{O}$ at different gelator concentrations (a). FTIR spectra of pure MATBTU (green curve) and DMSO (black curve) are also shown. Spectral regions containing the $\mathrm{VC}=\mathrm{O}$ of MATBTU $(\mathrm{b})$ and $\mathrm{vS}=\mathrm{O}$ of DMSO (c).

\section{Vibrational Circular Dichroism (VCD)}

The VCD spectra of gels of $\mathbf{1}$ and $\mathbf{2}$ in DMSO- $\mathrm{H}_{2} \mathrm{O}$ are shown in Figure 6, which also includes the calculated infrared and VCD spectra. VCD spectra of gels made in DMF- $\mathrm{H}_{2} \mathrm{O}$ and toluene could not be measured due to solvent signal overlapping. We have removed the 1750 and $1600 \mathrm{~cm}^{-1}$ the spectra as the chiroptical signal from water molecules is not significant. The main outcome was the negative feature observed for the carbonyl stretching mode. In addition, the $v(C=O)$ band of 2 appeared as a doublet, while a single band was observed in the VCD spectrum of 1 . This fact is in agreement with the shoulder at ca. $1798 \mathrm{~cm}^{-1}$ measured in the corresponding FTIR band of 2 (Figure S2, ESI), which was not observed for 1 (Figure 5b).
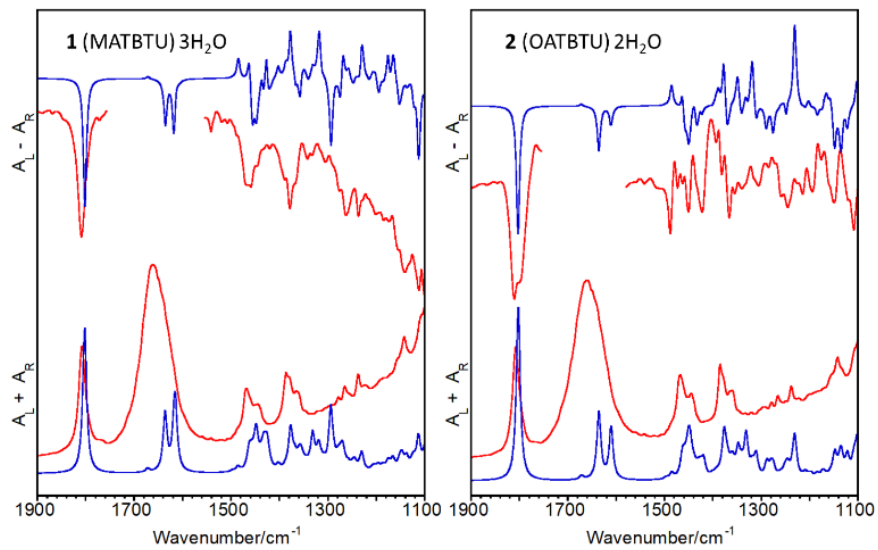

Figure 6. VCD (above) and infrared (below) spectra of 1 MATBTU (left panel) and 2 OATBTU (right panel) in DMSO- $\mathrm{H}_{2} \mathrm{O}$. Red lines: experimental FTIR spectra of gels in DMSO- $\mathrm{H}_{2} \mathrm{O}$. Blue lines: calculated b3lyp/cc-pvdz spectra of $\mathbf{1}-3 \mathrm{H}_{2} \mathrm{O}$ and $\mathbf{2}-2 \mathrm{H}_{2} \mathrm{O}$ hydrogen bonding complexes.

The negative VCD feature for the carbonyl stretching mode was correctly predicted by DFT calculations. However, calculations also indicated that the sign of this band was strongly dependent of the dihedral angle between the ester group and the aliphatic polycyclic moiety. Thus, and in order to reach the absolute configuration of these molecules, two different conformations of $\mathbf{1}$ and $\mathbf{2}$ were successfully optimized and their VCD spectra were calculated (Figure S5, ESI). In spite that all the geometrical parameters were allowed to vary independently, only two conformers were successfully stabilized, which differed on the orientation of the ester group with respect to the polycyclic moiety. By looking their VCD spectra, the only robust difference between the two conformers was the sign of the carbonyl stretching band, which was positive for the $\mathbf{A}$ conformers and negative for the $\mathbf{B}$ ones.

The optimized parameters were quite similar for $\mathbf{1}$ and $\mathbf{2}$. The conformers with negative carbonyl stretching feature, $\mathbf{1 A}$ and 2A, were always the most stable. The calculated energy gaps were $2.342 \mathrm{~kJ} / \mathrm{mol}$ for 1 and $2.181 \mathrm{~kJ} / \mathrm{mol}$ for 2 . The calculated $\mathrm{O}=\mathrm{CO}-\mathrm{C}-\mathrm{CH}$ dihedral angles, which defines the relative position of the ester group, were -25.2 and -25.7 deg for $\mathbf{1 A}$ and $\mathbf{2 A}$, respectively, and 136.3 and $138.0 \mathrm{deg}$ for the less stable conformers, 1B and 2B, respectively. Taking into account the negative sign of the experimental $v(C=O)$ bands, these data indicate that the chiroptical signal come largely from the $\mathbf{A}$ conformer, which can be proposed as the absolute configuration for gels of $\mathbf{1}$ and $\mathbf{2}$. In the case of $\mathbf{2}$, the negative doublet evidences at least two different environments in the gel. Despite the good matching between calculated and experimental FTIR spectra, the VCD spectra of $\mathbf{1}$ and $\mathbf{2}$ are barely reproduced in the $1500-1100 \mathrm{~cm}^{-1}$ region. This is largely caused by the high conformational freedom of hydroxyl and methyl 
groups, which have several bending vibrations in this region, and by the effect of the intermolecular forces into the gel, which cannot be simulated by our gas-phase calculations.

\section{X-ray diffraction (XRD) Studies}

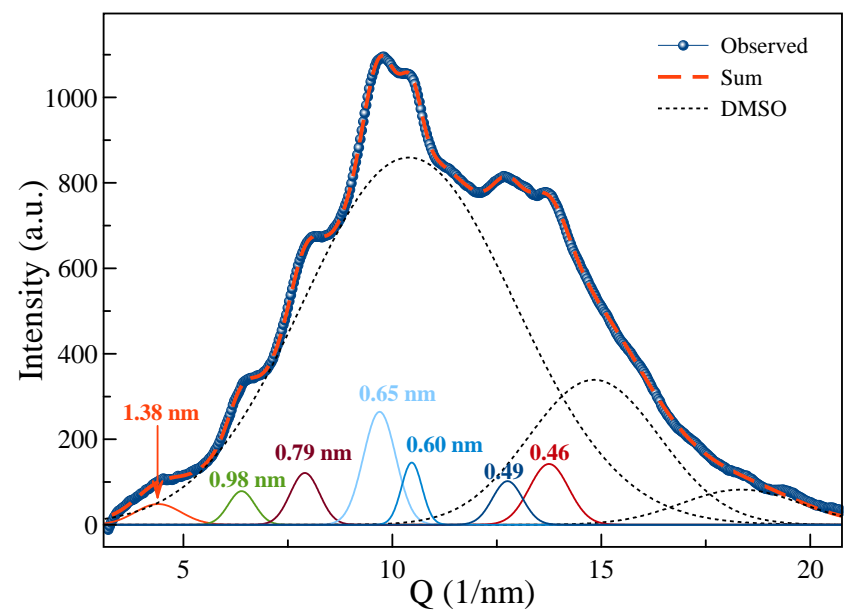

Figure 7. XRD pattern of gel 1 in $\mathrm{DMSO}-\mathrm{H}_{2} \mathrm{O}$. A non-linear fitting has been used to determine the position of the diffraction peaks. The dotted lines represent the diffuse scattering of the DMSO- $\mathrm{H}_{2} \mathrm{O}$ solvent.

X-ray diffraction pattern of MATBTU gel in DMSO- $\mathrm{H}_{2} \mathrm{O}$ is depicted in Figure 7. It shows an intense diffuse scattering (dotted lines) from the solvent and non-crystalline material. In addition, some reflections corresponding to $d$-spacing $(d=2 \pi / Q)$ of $1.38,0.97,0.78,0.64,0.61$ and $0.50 \mathrm{~nm}$ are observed, which verify the lamellar structures of the fibers. This structure is practically maintained after drying the hydrogels, as confirmed by XRD (Figure S6, ESI). Moreover, the diffraction patterns of the xerogels of compounds $\mathbf{1}$ and $\mathbf{2}$ in DMSO and DMF were very similar (Figure S6, ESI). On the other hand, the XRD pattern of the xerogel of $\mathbf{1}$ in toluene was completely different. It showed better-defined Bragg diffraction peaks indicating that the fibrils contain longer range-order in comparison to the fibrils obtained in DMSO and/or DMF (Table S3). We could use DFT calculations to assign the reflections to the corresponding intramolecular distances (Table S3 and Figure S7, ESI). The preferential dimensions of the optimized compound 1 (MATBTU) is shown in figure S7. Values from 0.54 to $0.75 \mathrm{~nm}$ correspond to the vertical length of the triterpene skeleton and values from 0.89 to $1.61 \mathrm{~nm}$ correspond to the horizontal length of the derivative from different views. XRD patterns of the compound $\mathbf{1}$ xerogel from toluene showed similar peaks as DFT calculated corresponding to d-spacings of 2.20,1.61, 1.48, 1.10, 0.89, 0.75, 0.65 and $0.54 \mathrm{~nm}$. The value measured at $2.20 \mathrm{~nm}$ can correspond to the double of the molecular length suggesting the formation of a dimer as depicted in figure $S 8$, in which the aromatic rings are twisted and interacting by $\pi$-stacking. This dimer leaves triterpene skeletons exposed to the exterior favouring the growth of the structure by intermolecular Van der Waals interactions between the triterpene skeletons.

\section{Rheological studies}

Amplitude sweeps (see Figure 8) demonstrated for all samples a typical gel-like behavior, characterized by values of the storage modulus $\left(G^{\prime}\right)$ much larger than the values of the loss modulus $\left(G^{\prime \prime}\right)$ within the region of low enough shear strain amplitude, for which both $G^{\prime}$ and $G^{\prime \prime}$ were approximately independent of the shear strain amplitude. This region of independence of the viscoelastic moduli with the value of the shear strain amplitude is known as linear viscoelastic region (LVR). At higher values of the shear strain amplitude an initially smooth drop of $\mathrm{G}^{\prime}$ is observed, accompanied by a smooth increase of $G^{\prime \prime}$, which reflects the onset of the nonlinear viscoelastic regime for which rupture of the gel structure takes place. Them, a maximum in $\mathrm{G}^{\prime \prime}$ is obtained, which represents the maximum dissipation of energy associated to the breakage of the gel structure. Results of frequency sweeps also demonstrated a typical behavior of a gel, with $G^{\prime}$ almost independent of the frequency and G" increasing slightly with this magnitude (Figure S9, ESI).

When gels were formed by capturing atmospheric water in DMSO, homogeneous gels containing higher concentrations of the gelators were possible. With respect to gel $\mathbf{1}$ (MATBTU), measurements performed at increasing gelator concentration (Figure 8A) showed a monotonic increase of the values of both $\mathrm{G}^{\prime}$ and $\mathrm{G}^{\prime \prime}$, and thus of the robustness of the samples. Even at the lowest gelator concentration of $1 \%(\mathrm{w} / \mathrm{v})$ gels were very stiff showing values of $\mathrm{G}^{\prime}$ higher than $10^{5}$. On the other hand, when toluene was used as solvent (Figure 8C), much lower (about two orders of magnitude) values of both $G^{\prime}$ and $G^{\prime \prime}$ were obtained (compare parts A and C of Figure 8). For gel 2 (OATBTU) a similar trend of concentration-stiffness dependence was also observed. In this case, this gelator was able to form stiffer gels than compound 1 , reaching values of $\mathrm{G}^{\prime}$ close to $10^{7}$ at $8 \%$ $(w / v)$. These high values of $G^{\prime}$ are not usual for these type of LMWGs which tend to be 4 order of magnitude lower. ${ }^{16}$

On the other hand, when gels were formed by direct addition of water, data demonstrated a weaker nature than for gels formed by capturing atmospheric water, see comparison in Figures $8 \mathrm{~B}$ and $8 \mathrm{E}$, both gels were measured at $1 \%(\mathrm{w} / \mathrm{v})$. This result highlights the influence that kinetic of gel formation has in the final macroscopic properties of the gels.

With respect to experiments aimed to the determination of $T_{\text {gel, }}$ differences were also observed based on the gelification protocol. For gels formed by capturing atmospheric water in DMSO, the typical trend is shown, as an example for gel 2 (OATBTU) at a gelator concentration of $1 \%(\mathrm{w} / \mathrm{v})$ in Figure S10, ESI. As observed, the values of $G^{\prime}$ and $G^{\prime \prime}$ did not change appreciably at low temperature (below approx. $35^{\circ} \mathrm{C}$ ). At this low temperature range $G^{\prime}$ was much higher than $G^{\prime \prime}$, as expected for a gel. On the other hand, at higher temperature, both $G^{\prime}$ and $G^{\prime \prime}$, but especially the former, decreased strongly, until finally they leveled off at temperatures above approx. 75 ${ }^{\circ} \mathrm{C}$. At this high temperature range $G^{\prime}$ was not appreciably higher than $\mathrm{G}^{\prime \prime}$, which definitely indicates that the samples were not a gel at these temperatures. As the transition temperature from a gel-like sample to a liquid-like sample $\left(T_{\text {gel }}\right)$, we took in this work the minimum temperature at which $G^{\prime}$ and $G^{\prime \prime}$ attained values only $10 \%$ higher than those values 
corresponding to the average of the high temperature plateaus. The obtained values for gel 1 (MATBTU) and gel $\mathbf{2}$ (OATBTU) at $1 \%(\mathrm{w} / \mathrm{v})$ of gelator concentration were respectively $75.1 \pm 2.2$ ${ }^{\circ} \mathrm{C}$ and $86 \pm 4{ }^{\circ} \mathrm{C}$ when they were formed by capturing atmospheric water, and $59.2 \pm 2.7^{\circ} \mathrm{C}$ and $63.1 \pm 0.6{ }^{\circ} \mathrm{C}$ when they were formed by direct addition of water. As expected, a lower $T_{\text {gel }}$ was obtained for gels formed by direct addition of water, in connection with their weaker nature, evidenced also as discussed above by smaller values of the viscoelastic moduli.

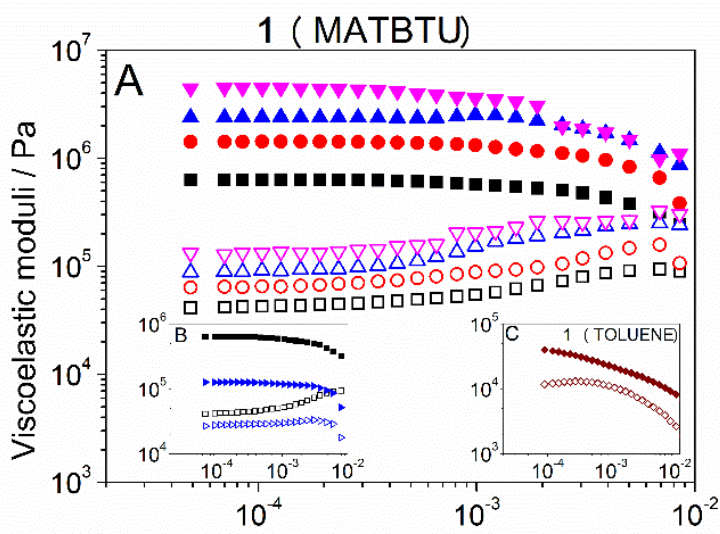

Shear strain amplitude / dimensionless

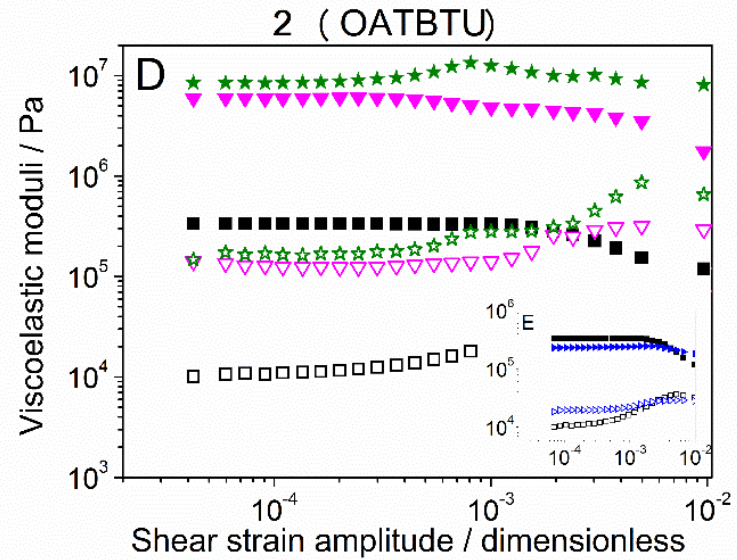

Figure 8. Amplitude sweeps: viscoelastic moduli as a function of shear strain amplitude, for oscillatory experiments of constant frequency $(1 \mathrm{~Hz})$ and increasing amplitude. A and B: gel 1 (MATBTU); C: gel 1 (MATBTU); D and E: gel 2 (OATBTU); Full symbols represent values of the storage modulus; open symbols values of the loss modulus. Gelator concentration (only gels formed by capturing atmospheric water): $\square \square: 1 \%$; $\diamond: 1.6 \%$

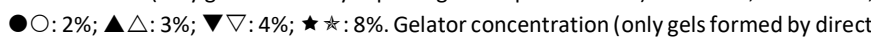
addition of water): $\triangleright: 1 \%$.

\section{Conclusions}

To sum up, in this work we have studied the capability of two new triterpenes derivatives (MATBTU and OATBTU) to form supramolecular gels. These two new compounds have some particularities not previously described for similar structuralrelated gelators, which make them highly relevant in the field of LMWGs. First of all, they have the ability to form gels by slowly capturing atmospheric water giving rise to homogeneous gels showing extremely high values of $\mathrm{G}^{\prime}$ up to $10^{7} \mathrm{~Pa}$. As previously commented, it is not trivial for a small compound to gelify upon the slowly interaction with an external agent since, as it has been described by most of LMWGs, gelification implies a nucleation and subsequent $1 \mathrm{D}$ growth. ${ }^{45}$ In this case, the slow gelification process subject to capture atmospheric water suggests that these two gelators must have a great tendency to grow into 1D fibers needed to form the gels. This assumption is confirmed by the long fibers and nanorods observed by SEM and TEM imaging. Quite remarkable is also the ability of these gelators to form homogeneous gels even at higher concentrations up to $10 \%(\mathrm{w} / \mathrm{v})$, which can also be justified by the great tendency of these molecules to self-assemble into fibers and by the slow gelification process. Nevertheless, NMR studies suggest that part of these gelator molecules can be free in solution exchanging with the gel network at room temperature. Notably also is the combination of solvent mixtures at which these molecules are able to form a gel. As shown by FTIR results, water is able to disrupt DMSO-DMSO interactions giving rise to $\mathrm{DMSO}-\mathrm{H}_{2} \mathrm{O}$ dimers that can be the responsible to trigger gel formation. This particular interaction between water and DMSO favors the formation of a more homogeneous environment in which the self-association of the gelator is promoted. Although gelators $\mathbf{1}$ and $\mathbf{2}$ only differ in an extra hydroxyl group, results have shown that these two structures interact differently. Primary results can be extracted by the solvents of different nature (table 1) that can partially gelify. Significantly, only compound $\mathbf{1}$ is able to gelify toluene and results showed that probably does by following a different aggregation pattern, as observed by XRD diffraction and TEM and SEM images. Nevertheless, VCD measurements supported by DFT calculations suggest that both compounds have a preferred and similar conformer in solution.

Rheological measurements have revealed that these DMSOgels, when formed by capturing atmospheric water, are very stiff, even at lower concentrations, having high values of $T_{\text {gel }}$. When water is directly added to the solution lower values of $G^{\prime}$ and G" and $T_{\text {gel }}$ are obtained. Weaker gels from 1 are obtained in toluene. The rheological data seem to be in agreement with the conclusions extracted with the other techniques and point out to the ability of these two gelators to form very homogeneous gels when capturing atmospheric water.

\section{Conflicts of interest}

There are no conflicts to declare.

\section{Acknowledgements}

Support from the Ministry of Economy and Competitiveness of Spain is acknowledged through the following project: FIS201785954-R (Agencia Estatal de Investigación, AEI, Spain, co-funded by Fondo Europeo de Desarrollo Regional, ERDF, European Union). K.V.G. thanks CONACYT (Consejo Nacional de Ciencia y Tecnología) GOBIERNO DEL ESTADO DE BAJA CALIFORNIA 2015 for her fellowship. G.B.R.R. thanks the Ministry of Economy and Competitiveness for a "Juan de la Cierva" contract. R.C.M. 
thanks the "Plan Propio de Investigación" from the UGR for the "Ayuda Puente" contract. J.M.D.L. thanks the Ministry of Economy and Competitiveness for a "Ramon y Cajal" contract (\#RyC-2016-21042). We also thank the "Unidad de Excelencia Química aplicada a Biomedicina y Medioambiente" (UGR) for support and CIC personnel of the University of Granada for technical assistance.

\section{Notes and references}

P. Terech and R. G. Weiss, Chem. Rev., 2002, 97, 31333160.

N. M. Sangeetha and U. Maitra, Chem. Soc. Rev., 2005, 34, 821-836. R. G. Weiss, J. Am. Chem. Soc., 2014, 136, 7519-7530.

E. R. Draper and D. J. Adams, Chem, 2017, 3, 390-410. R. Contreras-Montoya, A. B. Bonhome-Espinosa, A. Orte, D. Miguel, J. M. Delgado-López, J. D. G. Duran, J. M. Cuerva, M. T. Lopez-Lopez and L. Á. De Cienfuegos, Mater. Chem. Front., 2018, 2, 686-699. H. Wang and Y. Cheng, Mater. Chem. Front., 2019, 3, 472475. A. R. Hirst, B. Escuder, J. F. Miravet and D. K. Smith, Angew. Chemie - Int. Ed., 2008, 47, 8002-8018. B. Escuder, F. Rodríguez-Llansola and J. F. Miravet, New J. Chem., 2010, 34, 1044-1054. M. Conejero-Muriel, J. A. Gavira, E. Pineda-Molina, A. Belsom, M. Bradley, M. Moral, J. D. D. G. L. Durán, A. Luque González, J. J. Díaz-Mochón, R. Contreras-Montoya, Á. Martínez-Peragón, J. M. Cuerva and L. Álvarez De Cienfuegos, Chem. Commun., 2015, 51, 3862-3865. R. Contreras-Montoya, G. Escolano, S. Roy, M. T. LopezLopez, J. M. Delgado-López, J. M. Cuerva, J. J. Díaz-Mochón, N. Ashkenasy, J. A. Gavira and L. Álvarez de Cienfuegos, Adv. Funct. Mater., 2019, 29, 1-10.

11 P. W. J. M. Frederix, G. G. Scott, Y. M. Abul-Haija, D. Kalafatovic, C. G. Pappas, N. Javid, N. T. Hunt, R. V. Ulijn and T. Tuttle, Nat. Chem., 2015, 7, 30-37. P. G. Argudo, R. Contreras-Montoya, L. Álvarez de Cienfuegos, J. M. Cuerva, M. Cano, D. Alba-Molina, M. T. Martín-Romero, L. Camacho and J. J. Giner-Casares, Soft Matter, 2018, 14, 9343-9350.

13 H. Svobodová, V. Noponen, E. Kolehmainen and E. Sievänen, RSC Adv., 2012, 2, 4985-5007. M. Xue, K. Liu, J. Peng, Q. Zhang and Y. Fang, J. Colloid Interface Sci., 2008, 327, 94-101. Jeng, K. Liu, X. Liu, H. Xia, J. Liu and Y. Fang, New J. Chem., 2008, 32, 2218-2224.

16 M. Xue, D. Gao, X. Chen, K. Liu and Y. Fang, J. Colloid Interface Sci., 2011, 361, 556-564.

17 B. G. Bag and R. Majumdar, Chem. Rec., 2017, 17, 841-873.

18 E. E. Rufino-Palomares, A. Perez-Jimenez, F. J. Reyes-Zurita, L. G.- Salguero, K. Mokhtari, A. Herrera-Merchan, P. P. Medina and J. P. and J. A. Lupianez, Curr. Org. Chem., 2015, 19, 919-947.
2018, 148, 325-336.

N. Blanco-Cabra, K. Vega-Granados, L. Moya-Andérico, M. Vukomanović, A. Parra, L. Álvarez de Cienfuegos and E. Torrents, ACS Infect. Dis., 2019, 10.1021/acsinfecdis.9b00125.

B. G. Bag and S. S. Dash, Nanoscale, 2011, 3, 4564-4566. B. G. Bag and K. Paul, Asian J. Org. Chem., 2012, 1, 150154.

B. G. Bag and S. S. Dash, Langmuir, 2015, 31, 13664-13672.

B. G. Bag, S. N. Hasan, S. Ghorai and S. K. Panja, ACS Omega, 2019, 4, 7684-7690.

B. G. Bag, R. Majumdar, S. K. Dinda, P. P. Dey, G. C. Maity, V. A. Mallia and R. G. Weiss, Langmuir, 2013, 29, 17661778.

B. G. Bag, G. C. Maity and S. K. Dinda, Org. Lett., 2006, 8, 5457-5460.

Y. Gao, J. Hao, J. Wu, X. Zhang, J. Hu and Y. Ju, Langmuir, 2016, 32, 1685-1692.

Y. Gao, J. Hao, J. Wu, X. Zhang, J. Hu and Y. Ju, Nanoscale, 2015, 7, 13568-13575.

J. Lu, J. Hu, Y. Song and Y. Ju, Org. Lett., 2011, 13, 33723375.

Y. Gao, J. Hao, J. Liu, Y. Liang, F. Du, J. Hu and Y. Ju, Mater. Chem. Front., 2019, 3, 308-313.

R. Majumdar, S. Tantayanon and B. Gopal Bag, Chem. - An Asian J., 2016, 11, 2406-2414.

B. G. Bag, S. Das, S. N. Hasan and A. Chandan Barai, RSC Adv., 2017, 7, 18136-18143.

A. Martinez, A. Perojil, F. Rivas, A. Parra, A. GarciaGranados and A. Fernandez-Vivas, Phytochemistry, 2015, 117, 500-508.

M. Medina-O'Donnell, F. Rivas, F. J. Reyes-Zurita, A. Martinez, S. Martin-Fonseca, A. Garcia-Granados, R. M. Ferrer-Martín, J. A. Lupiañez and A. Parra, Eur. J. Med. Chem., 2016, 118, 64-78.

M. J. Frisch, et al., Gaussian 16, Revis. B.01, Gaussian, Inc., Wallingford CT, 2016.

A. D. Becke, J. Chem. Phys., 1993, 98, 5648-5652.

C. Lee, W. Yang and R. G. Parr, Phys. Rev. B, 1988, 37, 785789.

Y. Tawada, T. Tsuneda, S. Yanagisawa, T. Yanai and K. Hirao, J. Chem. Phys., 2004, 120, 8425-8433.

T. H. Dunning, J. Chem. Phys., 1989, 90, 1007-1023. T. J. Waybright, J. R. Britt and T. G. McCloud, J. Biomol. Screen., 2009, 14, 708-715.

B. Escuder, M. LLusar and J. F. Miravet, J. Org. Chem., 2006, 71, 7747-7752.

D. Miguel, S. P. Morcillo, A. Martín-Lasanta, N. Fuentes, L. Martínez-Fernández, I. Corral, M. J. Ruedas-Rama, D. J. Cárdenas, L. Álvarez De Cienfuegos, A. Orte and J. M. Cuerva, Org. Lett., 2015, 17, 2844-2847.

D. C. Duncan and D. G. Whitten, Langmuir, 2000, 16, 64456452.

V. M. Wallace, N. R. Dhumal, F. M. Zehentbauer, H. J. Kim and J. Kiefer, J. Phys. Chem. B, 2015, 119, 14780-14789. X. Huang, P. Terech, S. R. Raghavan and R. G. Weiss, J. Am. Chem. Soc., 2005, 127, 4336-4344. 